\title{
MATERNAL \& FETAL OUTCOME OF HYPERTENSIVE DISORDERS OF PREGNANCY- A STUDY OF 100 CASES, IN FMCH, FARIDPUR
}

\author{
SAHA MR ${ }^{1}$, KHAN JH ${ }^{2}$
}

\begin{abstract}
:
This prospective cross sectional study done at Faridpur Medical College Hospital (FMCH) during October 2005 to September 2006 to detect the maternal and fetal outcome in hypertensive disorders of pregnancy. Incidence of PIH in FMCH was 8.25\%. Among 230 patients admitted during the period due to hypertensive disorders of pregnancy consecutive 100 patients fulfilling the inclusion criteria was taken as the study cases. Eclampsia was the most common cause (72\%) and 49\% of the patient had positive family history of PIH. About half (49\%) of the patient were 33-36 years of age group. About complications of the Eclamptic patient 11\% had pulmonary oedema, 7\% developed CVA, 4\% patient developed ARF and one patient developed DIC. Fourty Eight percent patients delivered vaginally and LUCS done in 45\% Cases and two patients delivered by vacuum extraction.

About the fetal outcome 27\% were healthy, 25\% were premature and 14\% died at early neonatal period, 15\% were still birth and 7\% were IUD. Outcome of the baby delivered by LUCS were better than baby delivered vaginally. Ninety five percent (95\%) of the patient were alive and five patients died. Of them 3 due to pulmonary oedema and 2 due to CVA.
\end{abstract}

Key word: Eclampsia, pregnancy induced hypertension, Pulmonary oedema, CVA etc.

J Dhaka Med Coll. 2011; 20(2) : 183-187.

\section{Introduction:}

Hypertensive disorder of pregnancy is one of the commonest complications of pregnancy and a common cause of fetal and maternal morbidity as well as mortality. World wide ${ }^{1}$ pregnancy induced hypertension (PIH) is a complication which usually occur after 20 weeks of pregnancy as a direct result of gravid state $^{2}$. Pregnancy induced hypertension (PIH) may be associated with preeclampsia/ eclampsia or without gross oedema or protenuria that is gestational hypertension ${ }^{3}$. The aetiology of preeclampsia and eclampsia are not clearly known. A functional imbalance between vasodilations and vasoconstrictions play a major role in the pathophysiology of preeclampsia and eclampsia ${ }^{4}$ Vasospasm and related cellular hyperactivity has been suggested as the basic pathophysiologic event in this disease ${ }^{4}$ Endothelium related vasodilatation is impaired in patients with essential hypertension. Platelet activation and endothelial dysfunction disease are the major pathologic events of this disease. Some high risk factors leading to pre-eclampsia ${ }^{4}$ These are-

Specially young and elderly primigravida, Poor nutrition, Low level of education, Abnormal weight gain, Rising serum uric acid level, Presence of complicating factors e.g. like - preexisting hypertension multiple pregnancy, polyhydramnions, diabetes, nephritis etc.

The symptoms of hypertensive disorders are hypertension, oedema, sleep disturbance particularly at night, generalized or occipital headache, visual disturbance, epigastric discomfort, oliguria ${ }^{4}$. On examination- (I) weight gain> $0.5 \mathrm{~kg} /$ wk or $2.5 \mathrm{~kg} /$ month, (II) Rise in blood pressure- systolic blood pressure> $140 \mathrm{~mm}$ of $\mathrm{Hg}$ and diastolic blood pressure $>90$ $\mathrm{mm}$ of $\mathrm{Hg}$ with proteinuria, (III) Oedema (IV) Growth retardation of fetus ${ }^{4}$.

Several approaches in the prevention of preeclampsia has been tried, including calcium, magnesium supplementation and low dose aspirin, fish oil supplementation. For severe pre-eclampsia and eclampsia hospitalization is

1. Dr. Mukti Rani 'Saha, Resident Surgeon, Department of Gynae \& Obst., Dhaka Medical College Hospital, Dhaka.

2. Dr. Jaglul Haider Khan, Assistant Professor, Department of Gynae \& Obst., Dhaka Medical College Hospital, Dhaka.

Correspondence : Dr. Mukti Rani Saha 
required. Treatment of preeclampsia \& eclampsia includes general nursing care, control \& prevention of convulsions, control of maternal blood pressure, obstetric management.

\section{Materials and Method:}

It is a prospective cross sectional study done at Faridpur Medical College Hospital, Faridpur during October 2006 to Sept. 2005.

After admission, diagnosis was made mostly on the basis of history and clinical presentation with minimal laboratory aid. Informed consents were taken from all the study subjects or their relatives.

- Patients Suffering form essential hypertension in pregnancy

- Hypertension in pregnancy due to renal disease

- Pheochromocytoma and

- Thyrotoxicosis are excluded from the study.

\section{Methods:}

After admission diagnosis is made mostly on the basis of history clinical presentation and laboratory investigations of urine for albumin, S. Uric acid level and USG for pregnancy profile.

Patients blood pressure was checked in left lateral position at hourly and 6 hourly intervals according to severity and the urine was examined with heat coagulation test usually after admission. Data from individual patients were collected in prescribed data collection form.

Foetal monitoring is made by observing FHS, foetal movement, fundal height, foetal size and volume of amniotic fluid. In severe preeclampsia and Eclampsia magnesium sulphate was used according to the protocol of OGSB for prevention and control of convulsion and for control of hypertension a-methyldopa, nefedipin $\&$ hydralagin were used. Termination of pregnancy in eclamptic patient was done by the safest method.

Ethical permission taken from the Ethical committee of $\mathrm{FMCH}$.

\section{Results:}

During the study period 2786 patients were admitted in the Gynae department of $\mathrm{FMCH}$, of them 230 were due to hypertensive disorder in pregnancy. So the incidence was $8.25 \%$. Among the 100 study cases $72(72 \%)$ patients were due to eclampsia, of them 60 were antipartum eclampsia, $12 \%$ due to gestational hypertension and $13 \%$ due to gestational proteinuric hypertesnion (Table-I). Ninety three percent of the patients were house wife and $5 \%$ service holder and $2 \%$ student, Ninety five percent of the patients were Muslim and only $5 \%$ were Hindu. Sixty five percent $(65 \%)$ of the patients came from lower socioeconomic group (monthly income less than 3000 tk). Fourty Nine percent of the patient had positive family history and 30\% not known and 21\% negative family history.

\section{Table-I}

Case distribution of the patients

\begin{tabular}{lcc}
\hline & No & Percentage \\
\hline Gestational hypertension & 12 & 12 \\
Gestational proteinuric & 13 & 13 \\
hypertension & & \\
Eclampsia & 72 & 72 \\
Antepartum Eclp. & 60 & $83.33 \%$ \\
Intrapartum Eclp & 3 & $4.17 \%$ \\
Postpartum Elcp & 9 & $12.50 \%$ \\
\hline
\end{tabular}

About the complication of the eclampsia patient 11 patient had pulmonary oedema, 7 patients developed CVA, 6 had haematuria, 4 patients had ARF and 1 patient developed DIC (table-2).

Table-II

Complication of Eclamptic Patients (N-72)

\begin{tabular}{lcc}
\hline & No & $\%$ \\
\hline Pulmonary oedema & 11 & 15.3 \\
CVD & 7 & 9.7 \\
Haematuria & 6 & 8.3 \\
ARF & 4 & 5.6 \\
PPH & 3 & 4.2 \\
Hepatic failure & 3 & 4.2 \\
DIC & 1 & 1.4 \\
\hline
\end{tabular}


Fourty eight patients delivered vaginally and 45 patient delivered by LUCS and two by vacuum extraction (table-III). Among the 95 babies delivered 27 were term healthy, 25 premature, 14 babies died at their early neonatal period, 7 were IUGR, 15 stillborn and 7 IUD (table-IV). Five patients died undelivered. Fetus delivered by LUCS, 24 were healthy term, 8 were premature, 6 died at their early neonatal period and 2 were still birth (table V). Out come of the fetus delivered by LUCS were better than fetus delivered vaginally. Ninety five percent of the patient were alive and return home and five patient died, of them three due to pulmonary oedema and two due to CVD (Table-VII).

Table-III

Mode of Delivery (N-95)

\begin{tabular}{lcc}
\hline Mode & No & $\%$ \\
\hline Vaginal delivery & 48 & 50.5 \\
LUCS & 45 & 47.4 \\
Vacuum extraction & 2 & 2.11 \\
\hline
\end{tabular}

Table-IV

Fetal outcome (N-95)

\begin{tabular}{lcc}
\hline Healthy baby & 27 & 28.4 \\
Premature & 25 & 26.3 \\
Early neonatal death & 14 & 14.7 \\
IUGR & 7 & 7.46 \\
Stillborn & 15 & 15.8 \\
IUD & 7 & 7.4 \\
\hline
\end{tabular}

Table-V

Fetal outcome in patient undergoing caesarean section ( $N-45)$

\begin{tabular}{lcc}
\hline Outcome & 48 & Percentage \\
\hline Healthy term baby & 24 & 53.3 \\
Preterm & 8 & 17.8 \\
IUGR & 5 & 11.1 \\
Early neonatal death & 6 & 13.4 \\
Still birth & 2 & 4.4 \\
\hline
\end{tabular}

\section{Discussion:}

Maternal mortality due to hypertensive disorders of pregnancy in the developing countries is higher than the highly industrialized world. The prevalence of PIH was 93.1 per 1000 pregnancies in a population-based study in North Carolina, USA ${ }^{5}$.

Hypertensive disorders was 8.25 percent of total obstetric admission in FMCH. Eclampsia is the third major cause of maternal death ${ }^{6}$.

Table-VI

Fetal Outcome of patient undergoing vaginal delivery $(N-48)$

\begin{tabular}{lcc}
\hline Outcome & No & Percentage \\
\hline Healthy term baby & 20 & 41.67 \\
Preterm & 8 & 16.66 \\
IUGR & 8 & 16.66 \\
Early neonatal death & 10 & 20.83 \\
Still birth & 2 & 4.17 \\
\hline
\end{tabular}

The study which was done by hossain ${ }^{7}$ at Dhaka Medical College Hospital (DMCH) in 1993 showed the incidence to be 7.6 percent.

Table-VII Maternal Outcome

\begin{tabular}{lcc}
\hline Outcome & No & Percentage \\
\hline Alive & 95 & $95 \%$ \\
Died & 5 & $5 \%$ \\
Cause of Death & & \\
Pulmonary oedema & 3 & $60 \%$ \\
CVD & 2 & $40 \%$ \\
\hline
\end{tabular}

In the study of Jesimn ${ }^{8}$ at Mymensingh Medical College Hospital (MMCH) in 2000, the incidence was 11.45 percent. In the study of Khan ${ }^{9}$ in Bangabandhu Sheikh Mujib Medical University (BSMMU) in 2003, the incidence was 7.1 percent. In the study of N. Nahar in $\mathrm{DMCH}$ in 2004 the incidence was 13.77 percent. In the study of captain Sayada Fatema Khatun in CMH Dhaka in 2002 the incidence was 10 percent. 
Table-VIII

Highest age incidence of hypertensive disorders in different studies.

\begin{tabular}{lccc}
\hline Study & Place of Study & Age group (years) & Incidence (\%) \\
\hline Hossain (1993) & DMCH & $21-25$ & 39.0 \\
N Nahar (2004) & DMCH & $16-20$ & 54.0 \\
Cap. Fatema (2002) & CMH (Dhaka) & $21-25$ & 37.75 \\
Present study (Oct. 2005-Sep. 2006) & FMCH & $20-24$ & 55.0 \\
\hline
\end{tabular}

Table-IX

Comparison of parity distribution of hypertensive disorders of pregnancy in different studies.

\begin{tabular}{lccc}
\hline Study & Place of Study & Primi-gravida (\%) & Multi-gravida (\%) \\
\hline Akhter (1994) ${ }^{12}$ & SSMC \& MH & 58.0 & 42.0 \\
N Nahar (2004) & DMCH & 70.0 & 30.0 \\
Cap. Fatema & CMH (Dhaka) & 57.5 & 42.5 \\
Present study (Oct. 2005-Sep. 2006) & FMCH & 57.5 & 42.5 \\
\hline
\end{tabular}

The age range in hypertensive disorder patients in this study was found to be from 1537 years. The highest incidence (55\%) was in the age group 20-24 years. Comparison of incidence of hypertensive disorders with age group found in some other studies are shown in Table-X.

\section{Table-X}

Incidence of patients taking antenatal care in difference studies.

\begin{tabular}{lcc}
\hline Study & Place of Study & Incidence (\%) \\
\hline Hossain (1993) & DMCH & 46.0 \\
Akhter (1994) & SSMC \& MH & 42.0 \\
N Nahar (2004) & DMCH & 32.0 \\
Present study & FMCH & 17.0 \\
(Oct. 2005-Sep. 2006) & & \\
\hline
\end{tabular}

In the present study, most of the patients were primigravida (74\%) and in Akhter's ${ }^{10}$ study, most of the patients were primigravida (58\%), N. Nahar study, most of the patients were primigravida (70\%), in cap. Fatema study, most of the patients were primigravida $(57.5 \%)$, reflecting that it is a disease of primigravida.

Most of the patients of this study belonged to lower socioeconomic status. In Hossain ${ }^{7}$ and Akhter ${ }^{10}$ and N. Nahar studies, it was also shown that majority of the patients came from lower class.

The disease Is related to positive family history of hypertension and also recurrence.

Fetal outcome in pregnancy induced hypertension is markedly worse. In this study, 15.80 percent babies were stillborn, 14.7 percent early neonatal death due to asphyxia, 26.3 percent premature, 7.46 percent intrauterine growth retarded and 28.4 percent were healthy. Comparative results in several studies are shown in Table-XIII.

Table-XI

Comparison of fetal outcome in hypertensive disorder of pregnancy in different studies.

\begin{tabular}{lcccccc}
\hline Study & $\begin{array}{c}\text { Place of } \\
\text { study }\end{array}$ & Health & IUGR & Pre-mature & $\begin{array}{c}\text { Early neonatal death } \\
\text { due to asphyxia }\end{array}$ & Stillborn \\
\hline Hossain (1993) & DMCH & 40 & 6 & 18 & 5 & 4 \\
Akhter (1994) & SSMC\&MH & 45 & 4 & 15 & 5 & 6 \\
Das (1997) & IPGMR & 80 & 4 & 8 & 4 & 4 \\
N. Nahar & DMCH & 31.25 & 8.33 & 23.95 & 10.41 & 21.80 \\
Present Study & FMCH & 28.4 & 7.46 & 26.3 & 14.7 & 15.80 \\
\hline
\end{tabular}


In this study, patients were conservatively treated with rest, sedation, anti-convulsive therapy $\left(\mathrm{MgSO}_{4}\right)$ and anti-hypertensive drugs in oral/sublingual or inject able form by single agent or more than single agent when indicated.

In this study, Caesarean section was 47.4 percent of which maximum was due to uncontrolled blood pressure and failure of progress of labour and rest for other concomitant indications for Caesarean section. In Akhter's ${ }^{10}$ study in SSMC \& MH in 1994, Caesarean section was 43 percent. All these patients were treated carefully and all of the cases recovered uneventfully. In this study, there was 5 maternal deaths ( 3 had pulmonary oedema and 1 had CVD). Which is approximately same to Hossain's ${ }^{7}$ study in DMCH in 1993 and Nahar (2004) study but Akhter's ${ }^{10}$ study in SSMC \& MH in 1994 was 2 percent, but Das's ${ }^{11}$ study, there was no maternal mortality.

\section{Conclusions:}

(Incidence of PIH in FMCH was 8.25\%

Most of the women (83) had no antenatal check-up and 93 percent were housewives and majority were illiterate. Majority of the patients $(60 \%)$ had antepartum eclampsia (72\%). Out of 100 patients, 50.5 patients were delivered vaginally. LUCS were needed in 47.4 percent. Among maternal complications commonest was eclampsia (72\%). Pulmonary oedema was most common complications and cause of death eclampsia patients and (3\%) Prenatal death was $37.9 \%$ and preterm babies were $26.3 \%$. Prenatal out come was better in patients delivered by caesarean section.

Improving the ANC services and raising the awareness among the patients fetal and maternal outcome of the patients with PIH can be improved.

\section{References:}

1. Dutta DC, The placental and fetal membranes. In: Textbook of obstetrics. $5^{\text {th }}$ ed. Calcutta: New Central Book Agency (P) Ltd. 2001:28-40.

2. Robson SC, Hypertnsion and renal disease in pregnancy. In: Edmonds DK, editor. Dewhurst's textbook of obstetrics and gynaecology for postgraduates. $6^{\text {th }}$ ed. Oxford: Blackwell Science Ltd., 1999:166-85.

3. Dutta DC. Hypertensive disorders in pregnancy. In: Textbook of obstetrics. $5^{\text {th }}$ ed Calcutta: New Central Book Agency (P) Ltd., 2001: 234-55.

4. Reynolds C, Mabie WC, Sibai BM. Hypertensive states in pregnancy. In: DeCherney $\mathrm{AH}$, Nathan L, editors. Current obstetrics and gynecologic diagnosis and treatment. $9^{\text {th }}$ ed. New York: McGraw-Hill Companies, 2003:338-53.

5. Das TR. Outcome of Hypertensive disorder of pregnancy in Institute of Postgraduate Medicine and Research, Dhaka: a study of 100 Cases (Dissertation) Dhaka: Bangladesh college of Physicians and Surgeons. 1997.

6. Cap. Fatema. outcome of hypertensvie disorder of pegnancy (Dissertation) CMH Dhaka: 2002.

7. Hossain F. Pregnancy outcome in hypertensive disorder of pregnancy in Dhaka Medical College Hospital: a study of 100 cases (Dissertation) Dhaka, Bangladesh College of Physicians and Surgeons, 1993.

8. Khan SA. Maternal and foetal outcome of hypertensve disorders of pregnancy in BSMMU in 2003 (Dissertation). Dhaka, Bangladesh College of Physicians and Surgeons, 2003.

9. Shahabuddin AKM, Hasnat M, Hamid T, Rahman AKMF, Perinatal outcome of eleampsia in a medical college Hospital. Bangladesh J Child Health 1996; 20: 8-14.

10. Akhter M. Study of hypertensive disorder of pregnancy in Mitfor Hospital (Dissertation). Dhaka, Bangladesh College of Physicians and Surgeons, 1994.

11. Jesmin ZF. Clinical study of hypertensive disorders of pregnancy in MMCH: a study of hundred cases (dissertation) Dhaka: Bangladesh College of Physicians and Surgeons, 2000. 